\title{
Sport Ireland Women In Sport
}

\author{
Nora Stapleton \\ Women in Sport Lead, Sport Ireland \\ Details
}

(C) Nora Stapleton. This work is licensed under the Creative Commons Attribution-NonCommercialNoDerivatives 4.0 International License. To view a copy of this license, visit http://creativecommons.org/licenses/by-nc-nd/4.0/.

\begin{abstract}
The challenges facing women and girls in sport have a long history and many interventions to address these challenges have occurred over the years. It is well documented that these challenges no longer simply apply to female's active participation in sport and physical activity but through all aspects of the sporting landscape, i.e. coaching, officiating, leadership, governance and visibility. Though time has seen improvements naturally, Sport Ireland financial support and dedicated women in sport programmes developed as a result have had positive impacts which are explored in this paper.Using information gathered through the work of Sport Ireland, its databases, commissioned reports, dedicated policies and via reports from National Governing Bodies and Local Sports Partnerships, this paper provides a more detailed insight into the history of the Sport Ireland Women in Sport programme as well as other areas that impact women and girls in sport. It tracks the evolution of the programme since the inception of funding in 2005 to how it is managed today, as well as outlining some of Sport Ireland's current Women in Sport (WiS) projects. In order to give a full overview, information is also contained on the history of funding allocated to female High Performance athletes in Ireland. Since the establishment of funding in 2005, the WiS programme set out to, and has successfully, reduced the gap in sports participation levels between men and women. It has now grown to much more than a participation programme with the launch of a policy providing strategic direction to ensure women have equal opportunity across all areas of sport. Now the same attention and commitment is shifting to coaching, officiating, leadership, governance and visibility. The availability of funding for women in sport is an important feature of the Sport Ireland Women in Sport programme. With over $€ 22$ m awarded to date, NGBs, LSPs and women and girls in society will continue to benefit from monetary grants received. While it is acknowledged that there is a lot more to do to ensure parity amongst males and females in the sporting landscape, it is the view that the work of Sport Ireland through its WiS programme continues to benefit society and is making grounds in areas where inequality, might still occur.
\end{abstract}

Keywords: Women in Sport; Sport Ireland; National Governing Bodies; Local Sports Partnerships; Policy; Funding

\section{Introduction}

Sport Ireland is the authority tasked with the development of sport in Ireland. This includes participation in sport, high performance sport, anti-doping, coaching and the development of the Sport Ireland Campus. Sport Ireland financially support over 100 sports organisations, which includes 60+ National Governing Bodies ${ }^{1}$ (NGBs) and 29 Local Sports Partnerships (LSPs). Of the NGBs, approximately 42 of these are all-island governing bodies with the

\footnotetext{
${ }^{1}$ The number of NGBs can change as sports reach NGB status and are eligible to apply for funding.
} 
remaining governing their sport in the Republic of Ireland only. Sport Northern Ireland also plays a key role in supporting all-island governing bodies. The LSP network is spread across the 26 counties of the Republic of Ireland. Sport Ireland was first established under the guise of the Irish Sports Council in 1999. The scope of this organisation was subsequently expanded to include responsibility for coaching (via Sport Ireland Coaching) and high performance sport (via the Irish Institute for Sport, now Sport Ireland Institute).

Sport Ireland's Mission is to:

- Communicate the value and lead the thinking on sport

- Promote an inclusive and fair culture

- Generate value from finite resources

- Build strong sports organisations

- Realise the concept of 'sport for life for everyone'

In April 2019, Sport Ireland released its National Policy on Women in Sport. This was the first of its kind, following the launch of funding for women in sport in 2005, and a number of policy developments since then. This paper provides a more detailed insight into the history of this national WiS programme. It tracks the evolution of the programme since the inception of funding in 2005 to how it is managed today, as well as outlining some of Sport Ireland's current Women in Sport (WiS) projects. Finally, the reader can explore the history of funding allocated for female athletes in Ireland. It is hoped that this will be a valuable contribution to this special issue by filling some gaps in knowledge about the policy domain and its operational challenges.

\section{State Funding for Women in Sport}

In June 2004, the ESRI presented Sport Ireland (then the Irish Sports Council) with its report on 'Sports Participation and Health Among Adults in Ireland'. This study showed that less than one in five women completed 30 minutes of physical activity on at least five days per week as recommended by the WHO. On foot of this report, Sport Ireland developed a Women in Sport (WiS) Programme in 2005 with the aim to "raise overall physical activity levels and support women's roles within funded bodies". This included the establishment of a project team to make recommendations on the allocation of funding. In the budget in December 2004, $€ 750,000$ was allocated to Sport Ireland for the purpose of encouraging women's participation in sport. The Department of Arts, Sport and Tourism provided the funding indicating that it was to be used to develop new and innovative initiatives as well as to support existing NGBs and schemes.

Interestingly, in March 2003, the Joint Committee on Arts, Sport, Tourism, Community, Rural and Gaeltacht Affairs decided to investigate issues relating to women in sport and appointed Deputy Jimmy Deenihan, T.D. as its rapporteur. A Report on Females and Sport was produced drawing on previous work of the Women in Sport Task Force (1997-98), chaired by Gina Menzies (former member of the Irish Sports Council), and from ongoing doctoral research by Dr. Katie Liston now teaching in University of Ulster. In July 2004, on the back of this report, the Joint Committee provided eighteen recommendations on women in sport. Coincidently, one of these recommendations stated, "The Irish Sports Council, the Government and related Departments with legislative responsibilities for the provision of sport should consider the provision of additional funding to any body or organisation that submits a programme initiative or scheme to increase female involvement in any aspect of sport". Whether or not one were ahead of the other in relation to its research and plans for women in sport, the result saw the establishment of the Women in Sport Programme in 2005. 
A more coordinated approach to women's participation in sport and physical activity required an evidence base from which to inform policy initiatives. In 2007, data extracted from the Irish Sports Monitor (ISM) highlighted a participation gradient of $15.7 \%$ between males and females in sport, defined in this report as the difference in activity levels between males and females. This data affirmed the need for targeted programme funding for WiS, and in the last 10 years or more, this gender participation gradient has reduced to 3\% (ISM 2019).

An alternative way of describing the participation gradient can be seen in the form of ratios in Figure 1. i.e. male participants in sport compared to female participants and similarly with club membership. As the gender split in the general population is almost 50:50, the ratio is a useful way of comparing activity levels and club membership of the two groups. Therefore, for every 100 women that are participating in sport there were 158 males in 2007; the equivalent figures for the 2019 were 100 females and 109 males respectively. For every 100 women that were sports club members in 2007, there were 175 men. For 2019, this stat only dropped to 152. The bold black line in Figure 1. represents the target of parity and highlights the gender participation gradient in both participation and sports club membership.

Since the introduction of the ISM in 2007, the gap between male and female sports participation has shifted. In contrast, however, we have seen a relatively poorer performance around club membership where the gap has only closed by about $2 \%$.

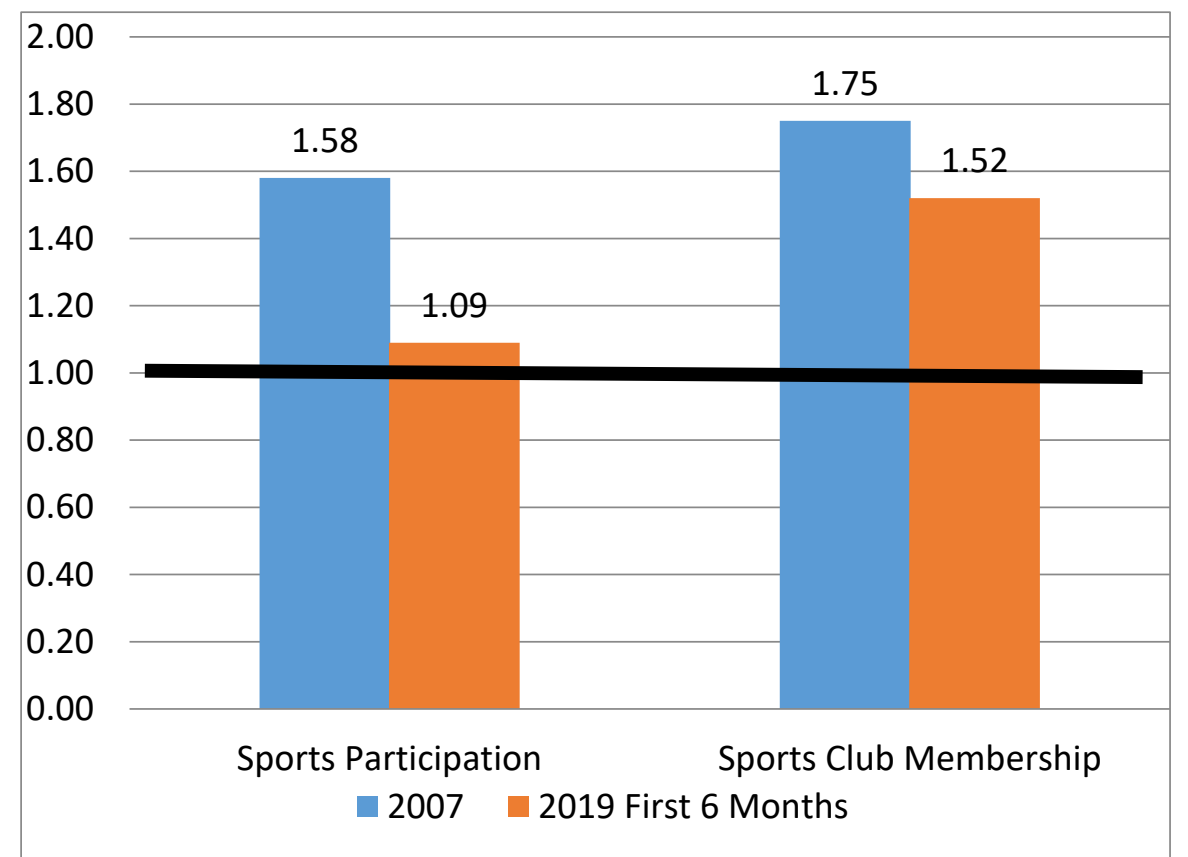

Fig 1. Analysis of sports participation and sports club membership between males and females in 2007 and 2019.

During a period of time (2007 to 2019) when sports participation was generally growing, as seen in data on club membership and in annual monitoring surveys, this narrowing of the gender gap is significant. Yet gendered patterns persist, such as women's greater involvement in particular leisure activities compared with men and, in the case of sports club membership, a gap persists in favour of men.

The difference in physical activity participation levels does not just exist between men and women. Results from The Children's Sport Participation and Physical Activity Study

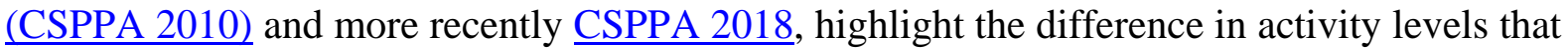
exist between boys and girls in both primary and post primary school. Therefore, when we discuss WiS programme funding for NGBs or LSPs, this funding supports initiatives that 
targeted all females, women and girls, in sport. Figure 2. below shows the stark difference in boys and girls participating in sport at least four times per week. This graph highlights community sport, i.e. outside of any activity that takes place in school and in particular, the significant drop off in participation by girls as they get older. The graph is a strong reminder that focusing on initiatives and interventions for adolescent girls is still a priority for Sport Ireland and its stakeholders.

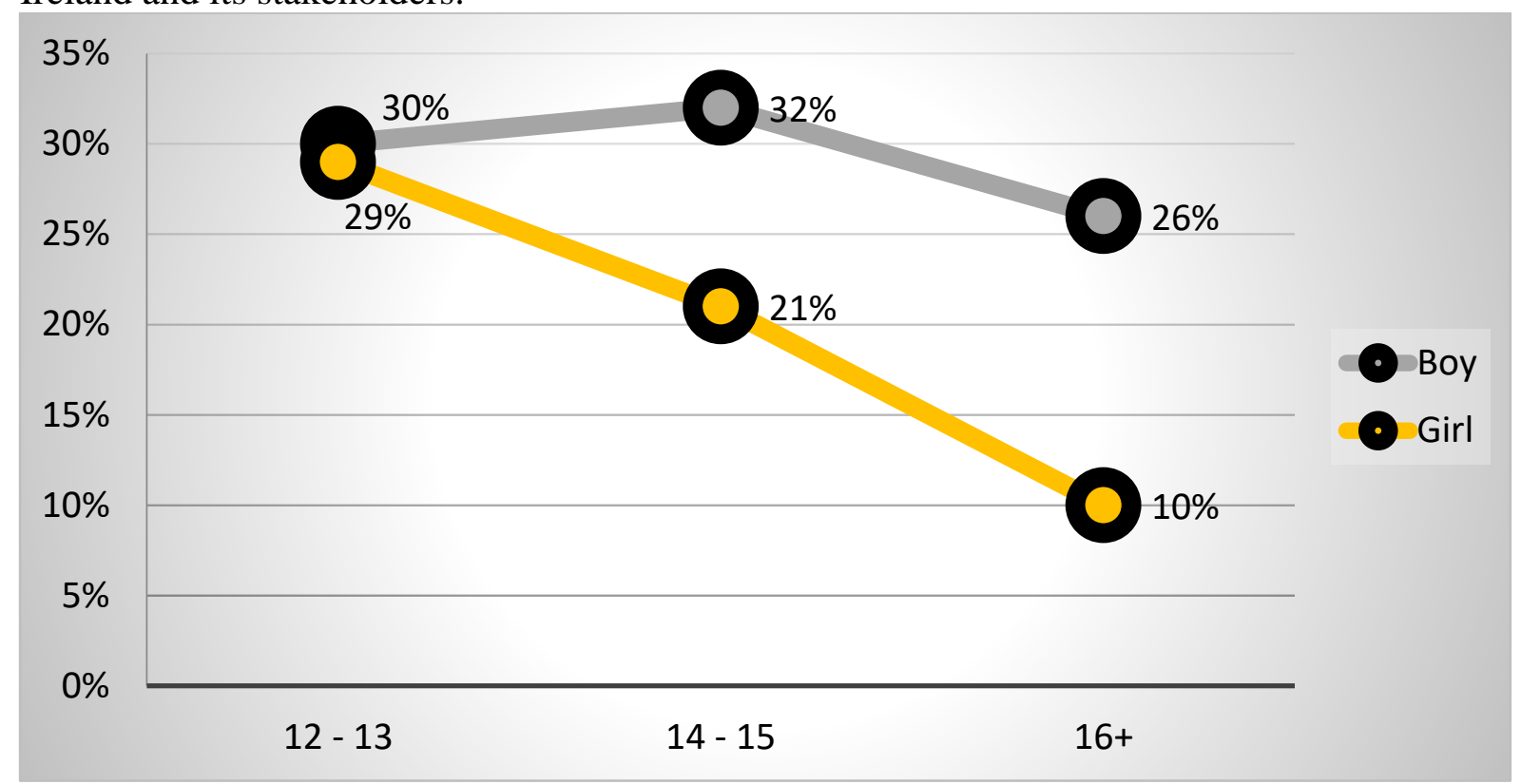

Fig 2. Proportion of post primary girls and boys playing community sport at least 4 times a week (CSPPA 2018)

Figure 3. provides a more comprehensive view of some of the comparisons and differences between girls and boys sports participation and physical activity. 


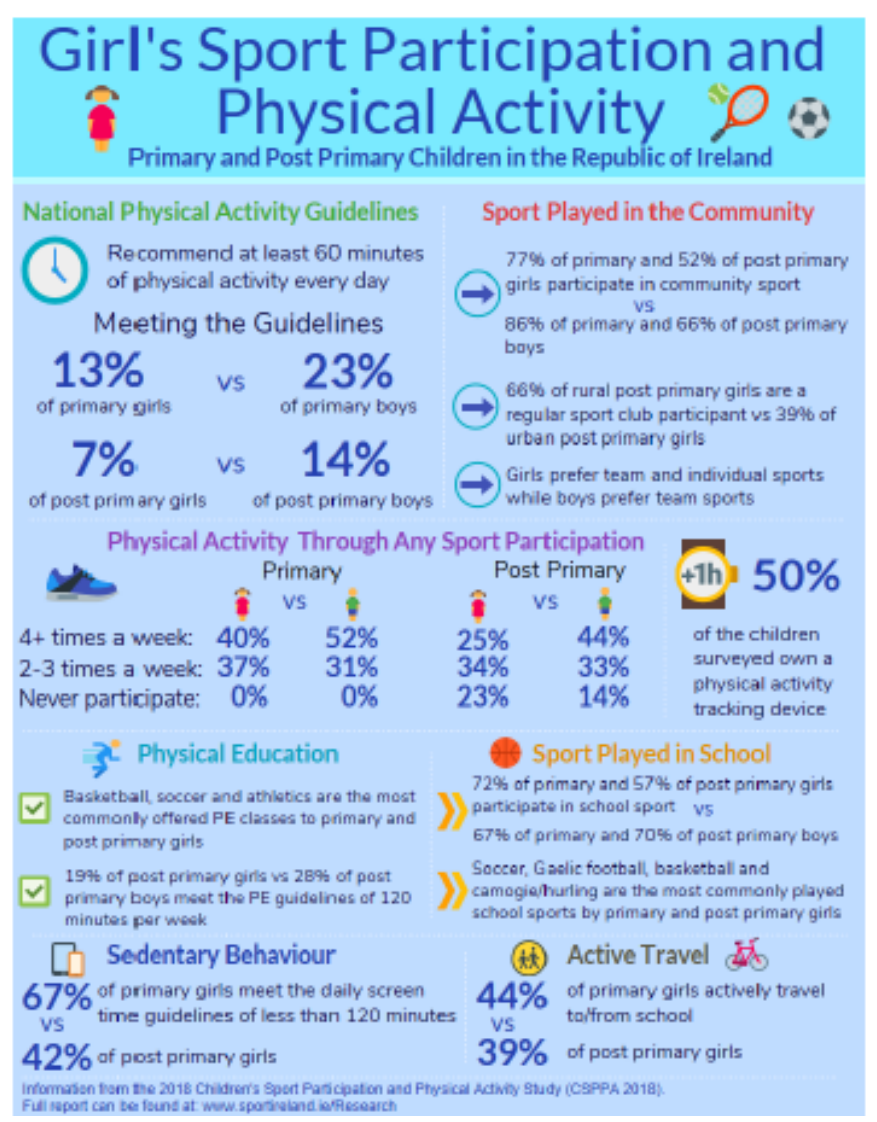

Fig 3. Girls Sport Participation and Physical Activity Analysis CSPPA 2018

Since the establishment of the WiS programme in 2005, Sport Ireland's commitment is visible through its budget allocation to WiS. Over $€ 22 \mathrm{~m}$ has been invested through the WiS Programme in National Governing Bodies and Local Sports Partnerships over the last fifteen years. This investment has supported the delivery of a variety of sports participation initiatives and the development of organisational capacity through the employment of women in a variety of full and part-time roles in the sports and leisure industries.

Figure 4. shows the budget $(€ \mathrm{~m})$ allocated to the Women in Sport Programme since it was first introduced in 2005. 


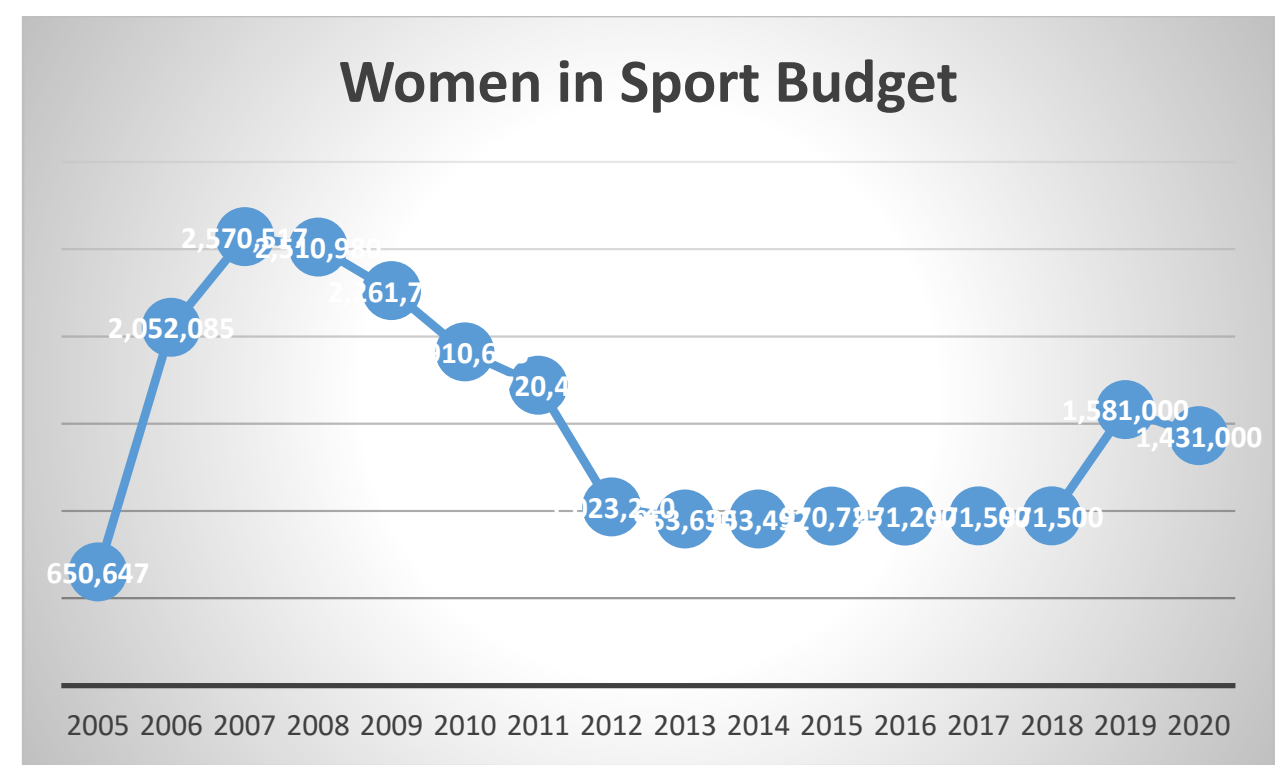

Fig 4. Sport Ireland Women in Sport Programme Funding

In Figure 5. the budget allocation to the Women in Sport Programme versus the total Sport Ireland budget ${ }^{2}$ is highlighted. It is important to note that the allocation of WiS funding is done on an application basis for selected initiatives/schemes in NGBs. This does not represent the total budget that might go towards the development of WiS in the NGBs/LSPs. Therefore, readers should not view these figures as the maximum amount of money dedicated towards WiS, as NGBs and LSPs do more for WiS outside of any dedicated budget issued by Sport Ireland. The funding of high performance female athletes is also not included in WiS funding. Athletes are funded through the Sport Ireland High Performance budget, which is discussed later in this paper.

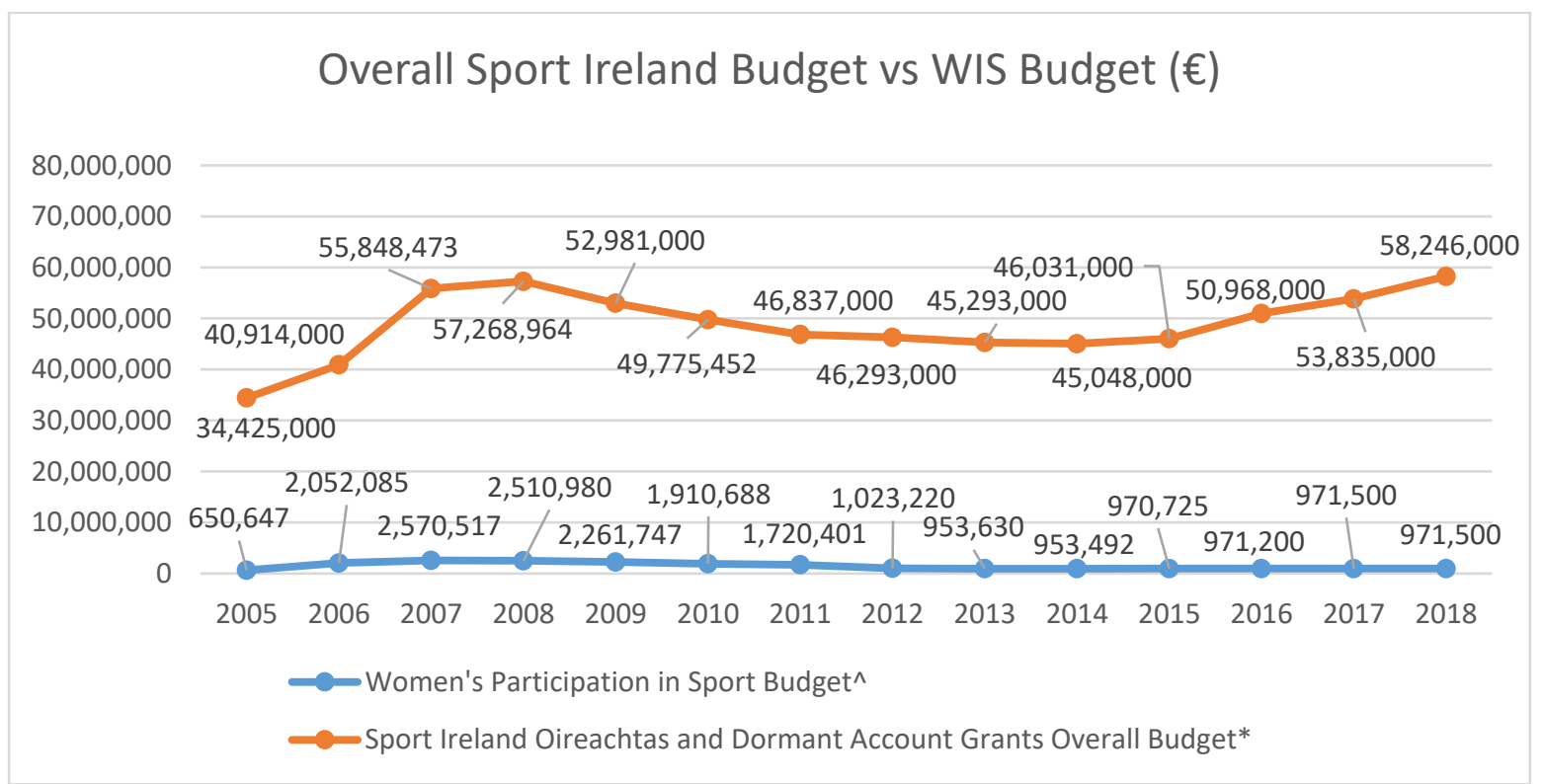

Fig 5. Women in Sport programme funding versus the total Sport Ireland budget

\footnotetext{
${ }^{2}$ Sport Ireland Oireachtas and Dormant Account Grants Overall Budget not including grants for Capital Expenditure
} 


\section{A New Chapter in the Women in Sport Programme}

In 2018, as part of a review of the Women in Sport Programme, Sport Ireland established the Women in Sport Project with three main objectives, namely to:

1. Develop an enhanced understanding of the current landscape for women's involvement in all areas of sport

2. Identify common barriers and opportunities for women in sport

3. Make recommendations to inform the development of future policies and programmes relating to strengthening women's involvement in sport.

The project came about as a way of ensuring the WiS Programme was still fit for purpose and to discover other areas of sport that required specific attention when it came to women's involvement.

Sport Ireland sought to hear as many voices through this project as the business and cultural case for diversity is now widely accepted, and the voices of males and females are critical to the future of sport in Ireland. Delivered by consultants Lisa Clancy and Sarah O'Shea, the project stimulated high levels of engagement. This included:

- focus groups ( $\mathrm{n}=150$ participants) in Dublin, Limerick, and Sligo;

- 2,923 responses to an online survey;

- 27 LSP and 46 NGB responses to a gender leadership survey, and;

- over 30 stakeholder engagements.

The project also reflected on international trends and best practice.

Through the work of the Women in Sport Project, and bolstered by Sport Ireland research, a strong evidence base was established that helped to shape the development of a policy for women in sport. Some of the key evidence produced included:

- Females accounted for $23 \%$ of board members of National Governing Bodies. (This figure represents all females on the board as reported by the NGB, whether elected, coopted, independent, etc.)

- The proportion of female Chairs of NGB Boards in sport (such as Athletics Ireland) was $23 \%$.

- Females accounted for $24 \%$ of paid CEOs across the NGBs.

- The number of females coaching in Ireland was 34\%, translated into a ratio of 2.5: 1 male to female coaches. This figure drops to under $20 \%$ at Level 3 and out of the 17 Performance Directors in Ireland, two are female and both were recruited from abroad.

- The ratio of male to female sports officiators was 2.3: 1 .

- According to the Irish Sports Monitor results in 2017, the gender gap in adult participation stood at $4.5 \%$. Females also accounted for $42 \%$ of adult sports club members.

- The 2018 Children's Sports Participation and Physical Activity study (CSPPA) confirmed the aforementioned drop-off and drop-out for teenage girls (see also Figures 2 and 3 previously mentioned).

- The proportion of sports print media articles devoted to women's sport in 2015 was $3 \%$.

Through the Women in Sport Project, national policies, and recognised national research, the Sport Ireland Policy for Women in Sport was developed. This was significant because of the benefits to be gained from putting the evidence horse before the policy cart, rather than vice versa. This policy identifies four key areas - leadership and governance; coaching and 
officiating; active participation; visibility - which have emerged as current gaps \& future opportunities for women in sport. From 2019 on, Sport Ireland aimed to target each of these four areas to deliver on the commitments of the policy on Women in Sport.

\section{Sport Ireland Policy on Women in Sport}

The policy expresses Sport Ireland's commitment to WiS and seeks to build on the significant work which has already been undertaken on this within the sport sector. In recognising the opportunity to make a significant impact on the lives of women through their involvement in sport, and in assigning it the status of a national policy initiative with statutory funding, it provides a blueprint for Sport Ireland's future work. The vision for women in sport is one where women have an equal opportunity to achieve their full potential, while enjoying a lifelong involvement in sport, i.e. as coaches, volunteers, club members, athletes, advocates, leaders, and participants from grassroots to the podium. The policy aligns with the Government's National Sports Policy 2018 - 2027 and the National Strategy for Women and Girls 2017-2020, and forms a key element of Sport Ireland's new corporate strategy. Importantly the policy acknowledges that women are not a homogeneous group: 'women' encompass those adults and youths of all ages, ethnic and socio-economic background, and is inclusive of all abilities.

To address the four identified target areas, Sport Ireland has discrete objectives assigned to each. The objectives and actions of the policy can be found below.

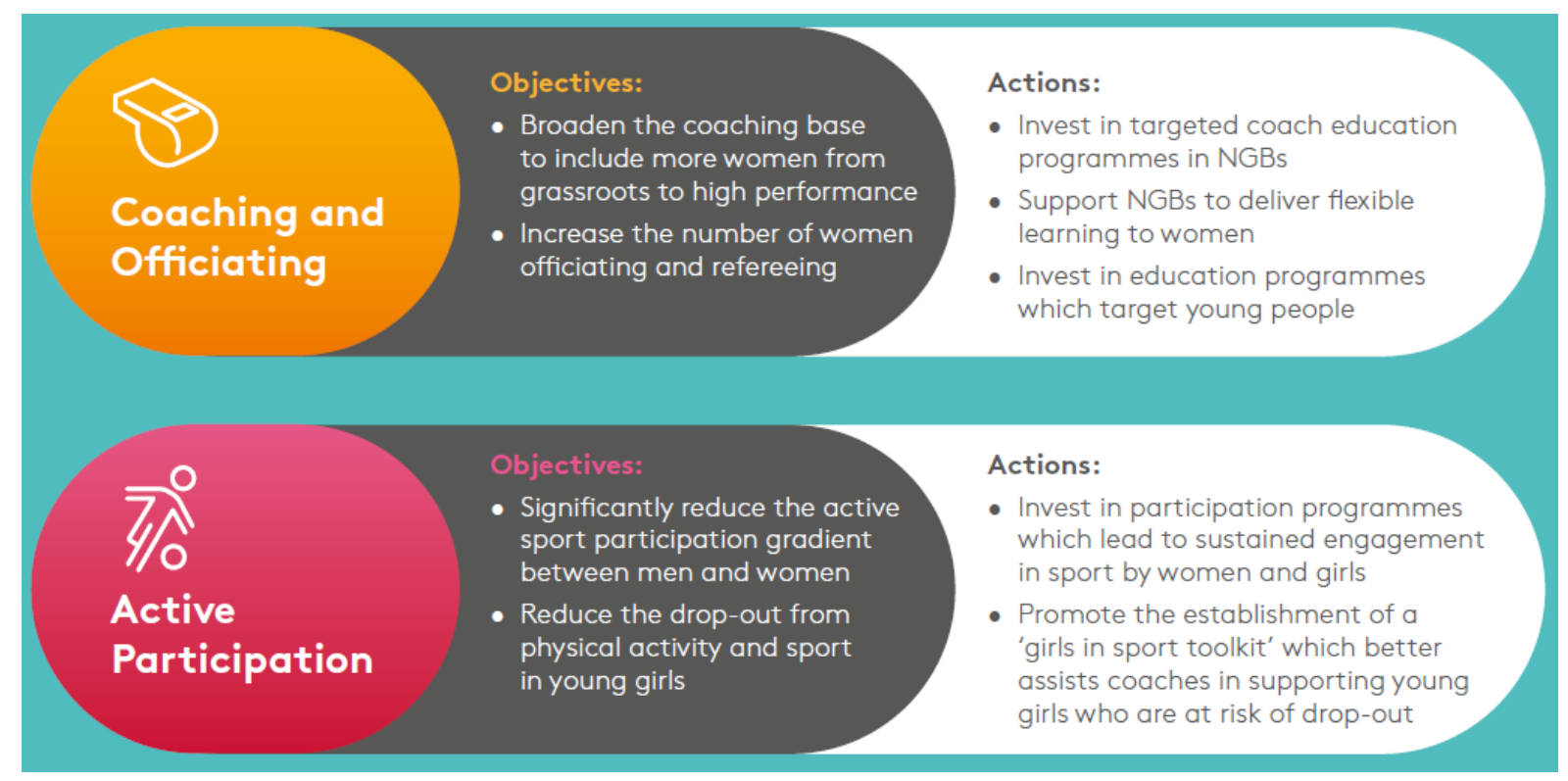




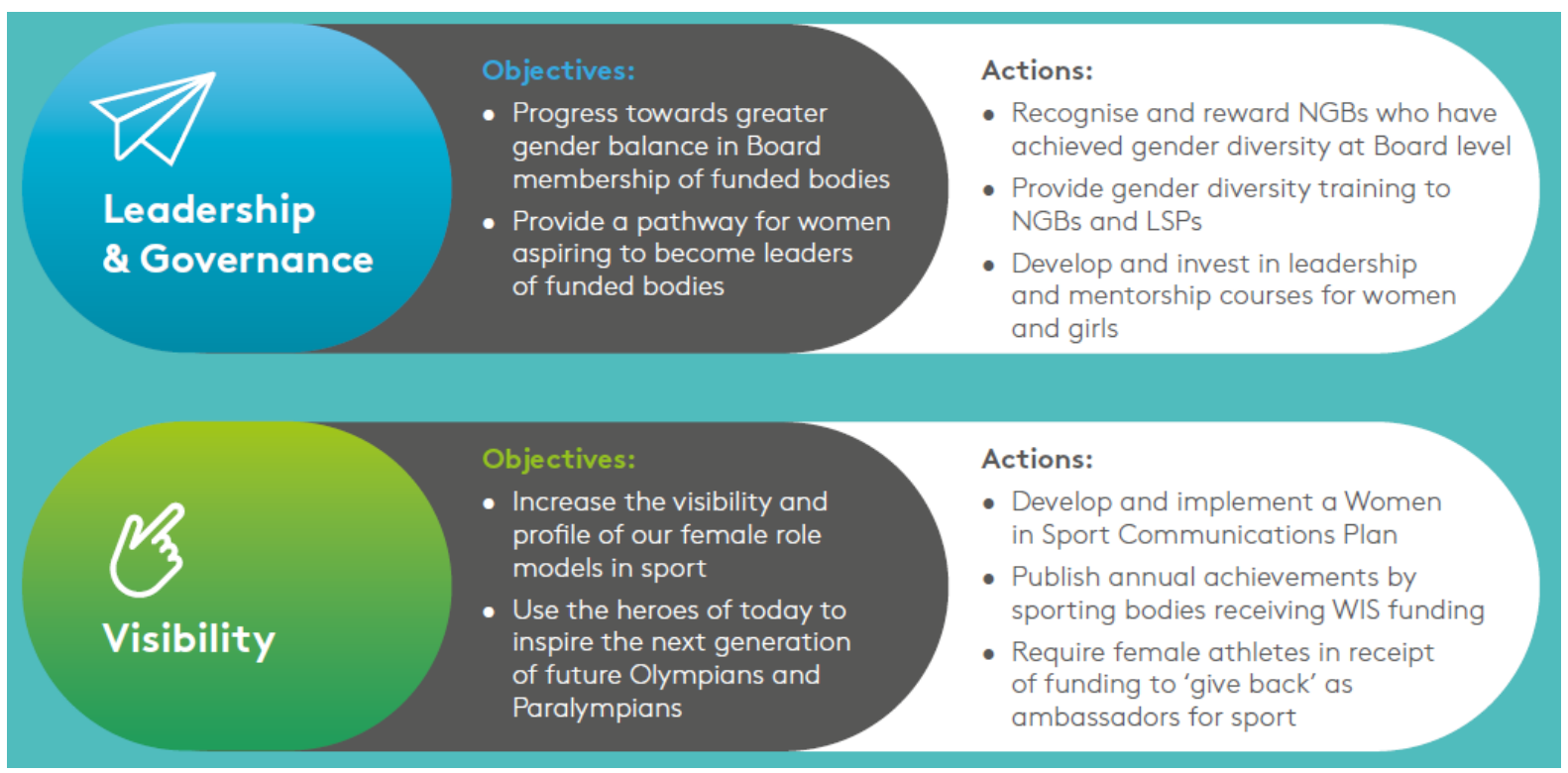

Fig 6. Objectives and Actions of the Sport Ireland Policy on Women in Sport 2019

To facilitate these objectives, three measures were put in place quickly that, whether by design or otherwise, mirrored recommendations in the 2004 Joint Committee Report. These were to appoint a WiS Strategic lead who would advocate for and implement the policy (the author); a relaunch of the WiS programme focusing more on investment in NGB and LSP-led sustainable initiatives under the four target areas of the policy; and, the establishment of a WiS Steering Committee to support the implementation of the policy and oversee the delivery of gender diversity targets and equality action plans.

This Steering Committee was established in March 2019 and currently consists of:

- Lynne Cantwell (Chair)

- Mary Dorgan

- Sarah Keane

- Mary O'Connor

- John Fulham

- Joanne Cantwell
- John Sweeney

- Frances Kavanagh

- Jenny Egan

- Claire Lambe

- Alan Milton

\section{Women in Sport Investment 2019}

Following the re-launch of the WiS Programme in 2019, NGBs applying for this investment were required to outline programmes/initiatives under one or more of the four key target areas of the policy. Recognising that effective and sustainable programmes require a long-term approach, Sport Ireland invested over €3million in the governing body sector to support the WiS programme. That investment covered a period of two years (2019 and 2020). Sport Ireland received 49 applications for funding in 2019. Based on these applications, funding was awarded to the 40 NGBs listed below in Table One below.

\section{Table One}




$\begin{array}{llll}\text { National Governing Body of } & \text { Total Investment } & \text { Total Investment } & \text { Total } \\ \text { Sport } & 2019 & 2020 & \text { Investment }\end{array}$

\begin{tabular}{|c|c|c|}
\hline Irish Rugby Football Union & $€ 120,000$ & $€ 120,000$ \\
\hline
\end{tabular}

Confederation of Golf $€ 100,000 \quad € 100,000 \quad € 200,000$

Athletics Ireland $€ 75,000 \quad € 75,000 \quad € 150,000$

Gymnastics Ireland

$€ 75,000$

$€ 75,000$

$€ 150,000$

Hockey Ireland

$€ 75,000$

$€ 75,000$

$€ 150,000$

Swim Ireland

$€ 75,000$

$€ 75,000$

$€ 150,000$

Tennis Ireland

$€ 75,000$

$€ 75,000$

$€ 150,000$

Basketball Ireland

$€ 50,000$

$€ 50,000$

$€ 100,000$

Cycling Ireland

$€ 50,000$

$€ 50,000$

$€ 100,000$

Rowing Ireland

$€ 50,000$

$€ 50,000$

$€ 100,000$

Triathlon Ireland

$€ 50,000$

$€ 50,000$

$€ 100,000$

Badminton Ireland

$€ 40,000$

$€ 40,000$

$€ 80,000$

Canoeing Ireland

$€ 40,000$

$€ 40,000$

$€ 80,000$

Irish Sailing

$€ 40,000$

$€ 40,000$

$€ 80,000$

Irish Wheelchair Association -

Sport

$€ 40,000$

$€ 40,000$

$€ 80,000$

Ladies Gaelic Football

Association

$€ 40,000$

$€ 40,000$

$€ 80,000$ 


$\begin{array}{llll}\text { National Governing Body of } & \text { Total Investment } & \text { Total Investment } & \text { Total } \\ \text { Sport } & 2019 & 2020 & \text { Investment }\end{array}$

\begin{tabular}{llll}
\hline Cricket Ireland & $€ 35,000$ & $€ 35,000$ & $€ 70,000$ \\
\hline $\begin{array}{l}\text { Irish Athletic Boxing } \\
\text { Association }\end{array}$ & $€ 35,000$ & $€ 35,000$ & $€ 70,000$
\end{tabular}

\begin{tabular}{lccc}
\hline Motorsport Ireland & $€ 35,000$ & $€ 35,000$ & $€ 70,000$ \\
\hline Mountaineering Ireland & $€ 25,000$ & $€ 25,000$ & $€ 50,000$ \\
\hline National Community Games & 25,000 & $€ 25,000$ & $€ 50,000$ \\
\hline Volleyball Association of Ireland $€ 25,000$ & $€ 25,000$ & $€ 50,000$ \\
\hline Irish Judo Association & $€ 20,000$ & $€ 20,000$ & $€ 40,000$ \\
\hline The Camogie Association & $€ 20,000$ & $€ 20,000$ & $€ 40,000$
\end{tabular}

Olympic Federation of Ireland $€ 20,000 \quad € 20,000 \quad € 40,000$

Paralympics Ireland \& CARA $€ 15,000 \quad € 15,000 \quad € 30,000$

\begin{tabular}{llll}
\hline Fencing Ireland & $€ 10,000$ & $€ 20,000$
\end{tabular}

\begin{tabular}{llll}
\hline GAA Handball & $€ 10,000 \quad € 10,000$ & $€ 20,000$
\end{tabular}

$\begin{aligned} & \text { Irish Olympic Handball } \\ & \text { Association }\end{aligned} € 10,000 \quad € 10,000 \quad € 20,000$

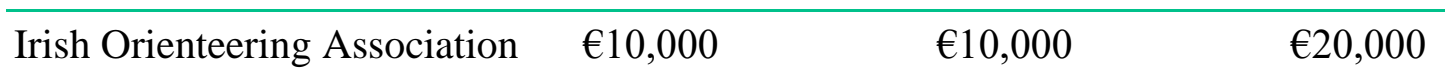

\begin{tabular}{llll}
\hline Irish Squash & $€ 10,000$ & $€ 10,000$ & $€ 20,000$
\end{tabular}

\begin{tabular}{llll}
\hline Irish Surfing & $€ 10,000$ & $€ 10,000$ & $€ 20,000$
\end{tabular}




\section{The Role of Local Sports Partnerships}

The Women in Sport Programme supports not just the NGBs, but also the network of 29 LSPs across Ireland. These LSPs undertake a wide range of actions with the aim of increasing sport and physical activity participation levels in their local communities. Of the 340,674 people who participated in LSP programmes across the country in 2020, $51 \%$ of these participants were female. 109,302 girls and 64,975 women took part in locally delivered participation initiatives from the LSPs. In addition to this, €265,000 was invested in the LSPs under the Women in Sport (WiS) Programme, which aims to increase women's participation in sport by providing and promoting participation opportunities for women, including women with a disability, women in disadvantaged communities, migrant women, older women and teenage girls. 18,161 women and girls took part in 130 local Women in Sport Programmes because of this funding.

\section{Sport Ireland Women in Sport Projects}

Since the relaunch of the Women in Sport Programme, the employment of the Women in Sport Lead, and the establishment of the Women in Sport Steering Committee, many programmes and initiatives have been supported within NGBs and LSPs. As well as this, many WiS projects are being undertaken by Sport Ireland under the direction of the WiS Lead (this author). The following are some examples of these projects.

\section{Sport Ireland Maternity Guidelines}

During the development of Sport Ireland's High Performance Strategy, athlete support was highlighted as a key area to advance within the high performance system. The strategy identifies the need to provide supports throughout key points of an athlete's career. Sport Ireland recognises that this includes female athletes who wish to have children and continue to compete in their sport following the birth of their child. Together with the National Governing Bodies of Sport (NGBs), Sport Ireland is committed to providing a safe and inclusive environment for all athletes. In order to provide the support mentioned above, $\underline{\text { Sport Ireland's }}$ Maternity Policy as part of the 2020 International Carding Scheme, ${ }^{3}$ was developed.

In 2020, the International Carding Scheme saw the introduction of a 12-month guarantee of funding to an athlete who becomes pregnant. To support this policy, a Maternity Programme was developed for the high performance community. This Programme, developed through collaboration between the Sport Ireland Institute, High Performance Unit, and Women in Sport Programme, details how all stakeholders can work together to achieve the objectives of the Maternity Policy. The responsibilities of the athlete, NGB, and Sport Ireland are specified, and the principles and conditions outlined in the document are expected to be adopted by all sports which are part of the International Carding Scheme.

\section{Women in Coaching Working Group}

A Women in Coaching Working Group was established in late 2019 as a sub-group of the Women in Sport Steering Committee. The purpose of the working group is to make recommendations to the Sport Ireland WiS Steering Committee in order to achieve the objectives and actions relating to coaching in the WiS Policy. One of the first projects proposed by this working group was the necessity to conduct a scoping survey of women in coaching. In

\footnotetext{
${ }^{3}$ The International Carding Scheme provides financial support to athletes for their training and competition programmes. The primary purpose of this funding is to support Irish athletes in reaching finals and achieving medals at European, World, Olympic and Paralympic level.
} 
2020, Sport Ireland undertook its first ever study exclusively targeting active and inactive female coaches across all sports on the island of Ireland. This project was combined work from the WiS Lead, Sport Ireland Research Unit and Sport Ireland Coaching. The aim of the survey was to:

- Develop a more in-depth understanding of the status of females in coaching roles on the island of Ireland

- Investigate the challenges and opportunities to increase the numbers of women coaching across all sports and at all levels; and

- Use the feedback to develop good practice programmes, resources or strategies available for NGBs and LSPs to utilise that will lead to successful recruitment, retention, development and progression of female coaches.

The survey achieved 2,421 responses from across 66 sports. In addition to the survey, six focus groups were conducted to explore women in coaching in more detail. In March 2021, Sport Ireland release its Women in Sport Coaching Research Report providing an overview of the research findings and key emerging themes which can be seen below. The report will support the development of a 'Women in Coaching Toolkit'. A resource to aid the sports sector in their recruitment, development and retention of female coaches.

\section{Coaching Girls Workshop Development}

Sport Ireland, with the help of Dublin City University, will soon launch a multi-sport coaching workshop for coaches of teenage girls. The project aims to upskill and educate coaches who have a direct impact on female players and keep them in sport. The overarching goal of the project is to address the dropout of teenage girls from sport/physical activity by supporting and educating the coaches.

\section{Adolescent Girls Get Active}

In order to address the low physical activity levels of girls, Sport Ireland sought to develop a resource for use by the sports sector (LSPs and NGBs) to support them in their development and implementation of sports programmes targeting adolescent girls.

\section{Launched in January 2021, the Girls Get Active Report discovered what really} matters in girls lives through five key anchors. By combining the exploration of girls' wider lives and what is important to them, with our understanding of their experiences and barriers in sport, the researchers developed eight important principles to engage and connect with teenage girls, to support them to embrace sport and physical activity into their lives. These are particularly valuable for girls who are less engaged currently, however can also be relevant for active girls to enhance their experience and prevent them from dropping out of sport. Sports organisations can use these Eight Principles for Success to check and challenge existing programmes to enhance appeal and relevance for the target audience. They can also be used to innovate and develop completely new initiatives through a teenage girl lens.

\section{Media Training Programme}

Visibility is one of the main pillars of the Women in Sport Policy. Sport Ireland believe that the importance lies not just with the visibility of female sports stars competing but also the visibility of females in positions of commentating on and analysing sports events. In March 2021, Sport Ireland launched its latest programme to help increase the number of visible female 
roles model in the sports media. The aim of the programme is to upskill female analysts and panelists across key sports in order to assist, prepare and support them in sports media roles.

The programme aims to provide training on pre, during, and post sport event analysis and punditry for broadcast (TV, live streaming, radio) for up to six identified candidates. The comprehensive training programme, gives candidates both a theoretical and practical understanding of working in a live studio environment, preparation \& research for broadcasts, on-air delivery, establishing area(s) of specialisation and establishing relationships with key stakeholders - broadcasters, players, officials and governing bodies.

\section{Board Composition Snapshot}

In March 2020, Sport Ireland released its first snapshot of board composition figures from across the NGB sector and progress made towards gender balance on boards. This snapshot highlighted that the number of females currently serving on the boards of NGBs has increased to $29 \%$, up from 24\% in March 2019. A second snapshot summarising women's leadership roles in NGBs and LSPs was released in December 2020. Information from this snapshot can be seen below. It is Sport Ireland's intention to continue to release a similar snapshot every 6 months in order to accurately reflect the current leadership environment in sporting organisations.

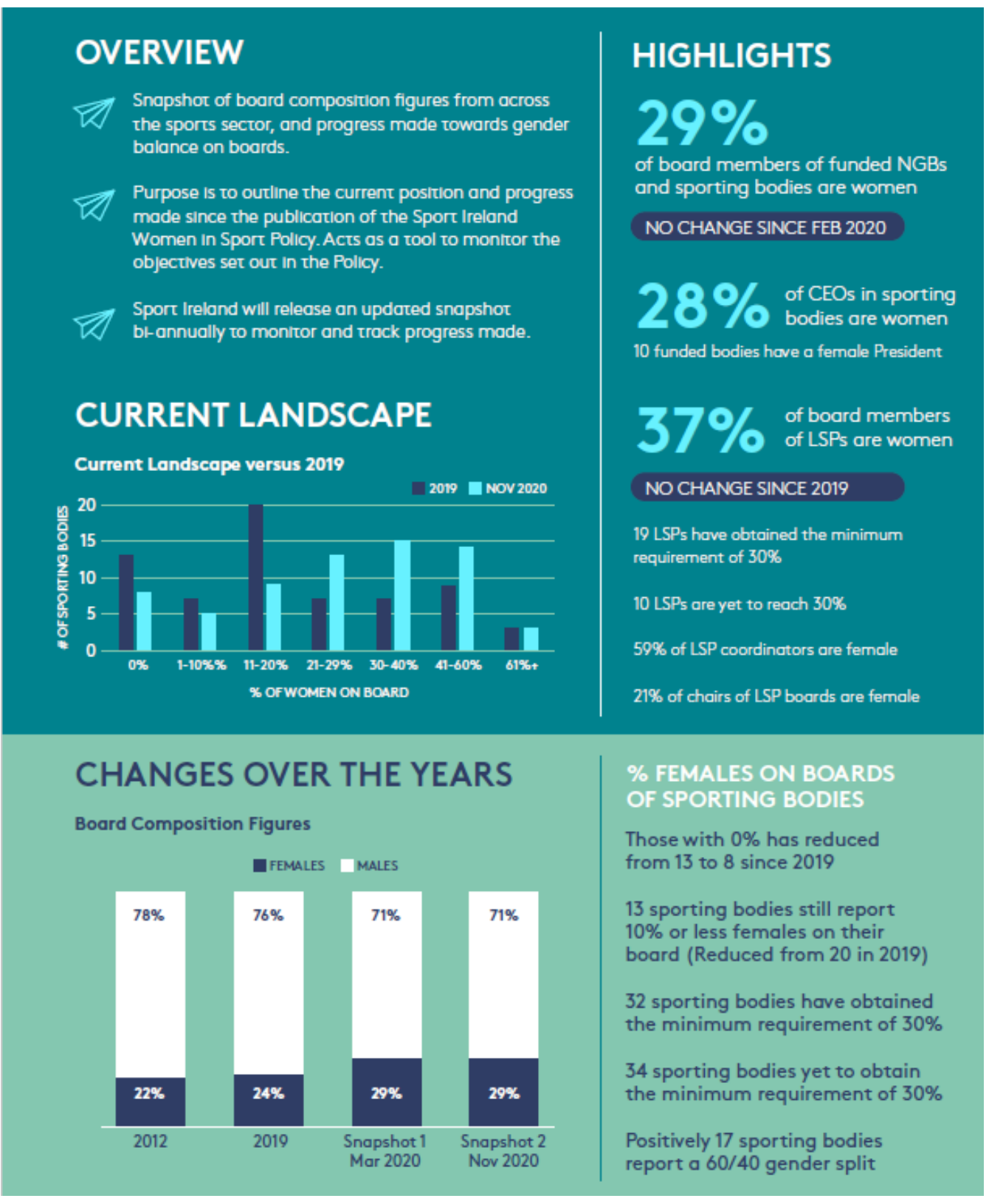




\section{Gender Diversity on Boards Resource}

Sport Ireland developed a resource for use by the sports sector (Local Sports Partnerships (LSPs) and National Governing Bodies (NGBs)) to guide and support them in developing more gender equal boards and committees. Launched in December 2020, the resource was developed in two parts. Part A outlines the business case for more gender diverse boards and uses examples from Ireland and the rest of the world to educate people on the topic. Part B is in the form of a toolkit and outlines practical measures and actions in the form of a 'best practice framework', which can be implemented in order to attract and retain female board members.

\section{History of High Performance Athlete funding - International Carding Scheme}

The International Carding Scheme provides financial support to athletes for their training and competition programmes. The primary purpose of this funding is to support Irish athletes in reaching finals and achieving medals at European, World, Olympic and Paralympic level. Currently the funding bands are split according to performance achieved with no gender difference. Those achieving Podium finishes receive $€ 40,000$, World Class receive $€ 20,000$ and International receive $€ 12,000$. Figure 7 below highlights Sport Ireland's financial support to athletes since 2005 .

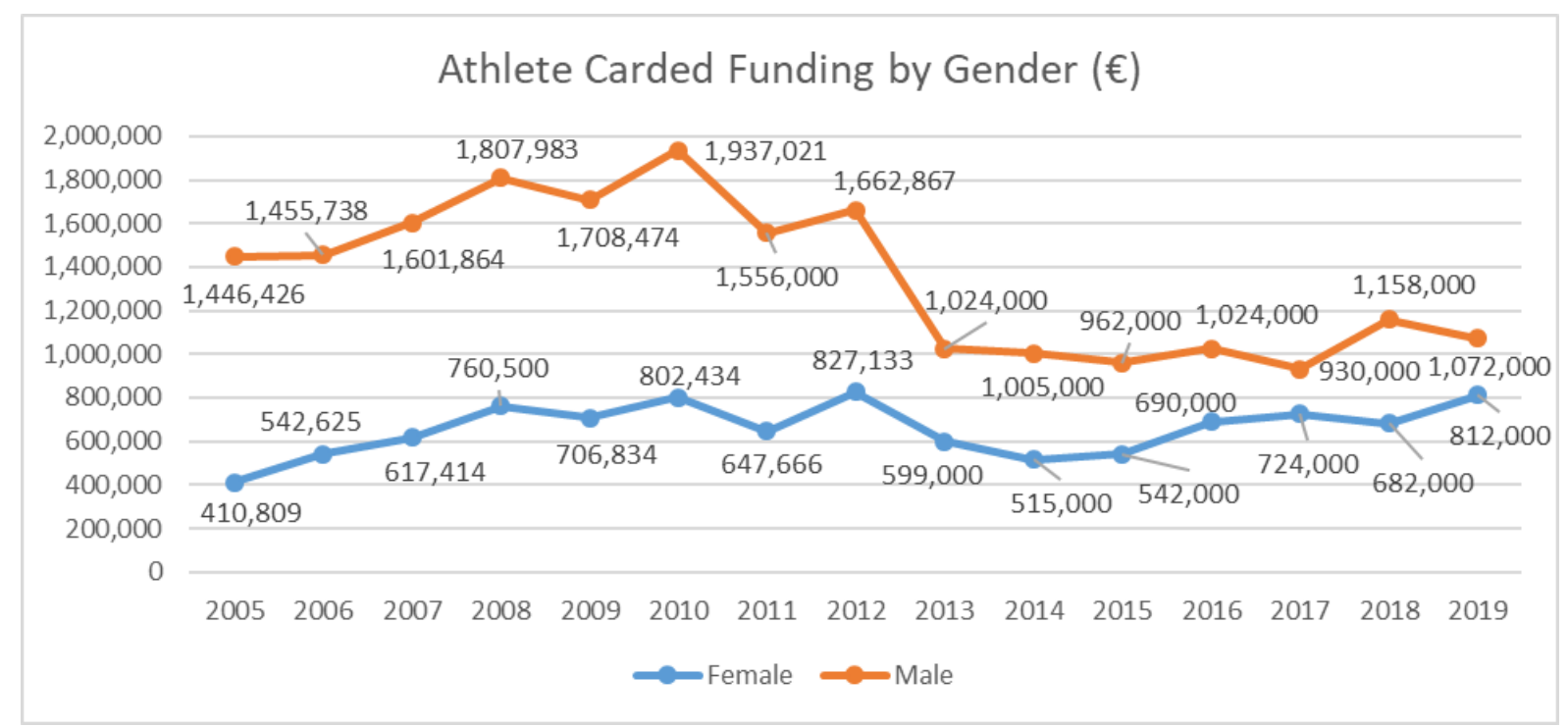

Figure 7. International Carding Scheme Funding (€) Split by Gender

The difference in funding awarded to male athletes versus female athletes is very noticeable from 2005 through to 2011. While the difference looks very stark, there are probably multiple reasons for the gap. Some would cite a lack of opportunities for female athletes to compete at levels eligible for funding; others would suggest that some NGBs did not yet have pathways in place for females to become high performance athletes. Figure 8 . below shows the number of athletes awarded funding under the International Carding Scheme by gender from 2005 through to 2019 . 


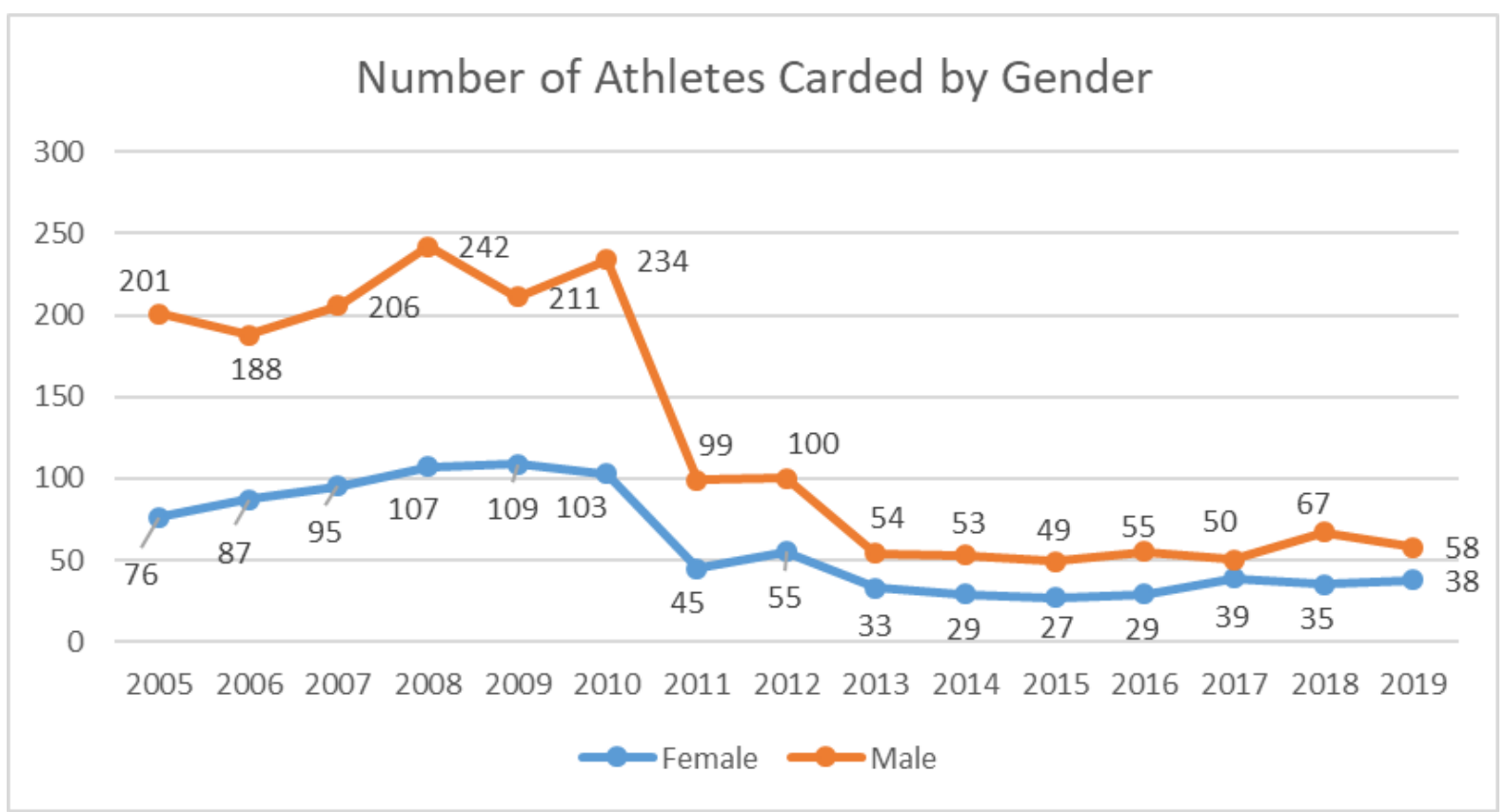

Fig 8. Number of Athletes in Receipt of International Carding Scheme Funding by Gender

The scheme has changed over the years and most of the changes you see in the graphs reflect reforms made by Sport Ireland. The landscape for women in sport has changed significantly.

Up until 2009/2010, there were too many athletes in general on the International Carding Scheme for it to be effective, and so Sport Ireland reformed the programme to reduce the overall number of athletes. In 2010, all junior or youth athletes were released from the scheme and the onus put back on the NGB to manage their development. The drop in athlete numbers in 2012 is reflective of those retiring post the 2012 Olympic Games.

While the data in Figure 8. shows that there are less female athletes receiving carded funding than male athletes, this is no longer due to a lack of opportunity within the NGBs or competition format. There are also now numerous sports that have more female carded athletes than males.

\section{Conclusion}

The information in this chapter on Women in Sport, has hopefully brought the reader on a journey of Sport Ireland's work and commitment to WiS. From its humble beginnings in 2005, the programme set out to, and has successfully, reduced the gap in sports participation levels between men and women. It has now grown to much more than a participation grants programme with the launch of a policy providing strategic direction to ensure women have equal opportunity across all areas of sport. Strides were made in reducing the gender participation gap since the programme introduction in 2005, now the same attention and commitment must be seen in coaching, officiating, leadership, governance and visibility.

The availability of funding for women in sport is an important feature of the Sport Ireland Women in Sport programme. With over $€ 22 \mathrm{~m}$ awarded to date, NGBs and LSPs will continue to benefit from monetary grants received. However, as the programme enters a new era, we should see more and more Sport Ireland projects through the WiS programme that will benefit the sports sector as a whole. Increasing activity levels amongst adolescent girls will continue to be a challenge but also a key priority of Sport Ireland. As we work through the 
objectives and actions outlined in the policy, we are confident and excited about the work and projects currently being developed under Sport Ireland's WiS programme.

Finally, while the funding and policy is vital to WiS at the minute, the aim is a future where policies and dedicated funding are no longer required. Nevertheless, there is still a huge challenge with society as a whole. Until everyone's perceptions of women playing and being involved in sport is equal to that of men, there will always be a need to dedicated WiS resources. Societal and cultural mindsets and traditions will continue to challenge the progression of women in sport but the environment is changing. 